\title{
The Analysis of the Structure and Style of Qur'anic Stories according to Shi'ite Interpretations
}

Ziba Kazemian kazemian@iaurasht.ac.ir

Faculty member, Department of Theology and Islamic Studies Islamic Azad University, Rasht, Iran.

\begin{abstract}
In the Holy Quran, numerous valuable and instructive concepts are presented as stories by God Almighty. As goals and works refer to a single truth, it should be pointed that the stories of the Holy Quran are a selective narration of previous nations with specific purposes. Accordingly, this article tries to open a new window onto the structure and method of Qur'anic stories based on an approach grounded in Shiite interpretations. The paper sets out to examine various dimensions of Qur'anic stories, exploring their aims, structure, and methods of processing. Hence, the elements of Quranic stories are examined base on a descriptive and analytical methodology. It is suggted that the act of narration in Quranic stories can be divided into past, present and future according to the time of events. Some Qur'anic stories narrate the stories of previous prophets and tribes to reduce the suffering of the Prophet and guide the true believers; some other stories chronicle the events of the present or future of the Prophet's era, describing the stories and events of the Prophet's life with his fellowmen; others foretell maily horrific future events that will occur sooner or later. The structure of Quranic stories, regardless of its fundamental and thematic differences with non-Quranic stories, i.e. the superiority of instructive dimensions in adhering to the elements of storytelling including characterization and element of time/place, enjoys an appealing and special form as it takes advantage of artistic textual elements.
\end{abstract}

Key words: Quranic stories, Shiite commentators, concepts, study of the structure and style of Quranic stories.

Citation: Kazemian, Ziba; Spring and Summer (2021). The Structure and Style of Qur'anic Stories According to the Opinions of the Shi'ite Interpreters, 2(4), 274-303. (In Arabic)

Studies in Arabic Narratology, Spring and Summer (2021), Vol. 2, No.4, pp. 274-303

Received:,July18 2021 Accepted:October27, 2021

CFaculty of Literature \& Humanities, University of Kharazmi and Iranian Association of Arabic Language \& Literature. 


\section{دراسات في السردانية العربية}

الرقم الدولي الموحد للطباعة: • م •

الرقم الإلكتروني الدولي الموحد: rVIV- - IV9

\section{بنية القصص القرآنية وأسلوبها بحسب آراء المفسرين الشيعة}

kazemian@iaurasht.ac.ir

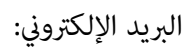

زيبا كاظميان

عضو هيئة التدريس في قسم الإلهيات والمعارف الإسلامية،جامعة آزاد الإسلامية ، رشت ، إيران.

الإحالة: كاظميان، زيبا. ربيع وصيف(آ·r). بنية القصص القرآنية وأسلوبها بحسب آراء

المفسرين الشيعة ، دراسات في السردانية العربية، ؟(ع)، عVץ-ץ.ب.

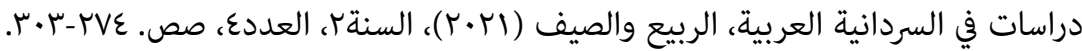

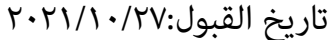

$$
\begin{aligned}
& \text { تاريخ الوصول: r/N/NA }
\end{aligned}
$$

() كلية الآداب والعلوم الإنسانية بجامعة الخوارزمي والجمعية العلمية الإيرانية للغة العربية

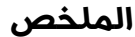

صورت العديد من الأمور القيمة والمفيدة على شكل قصص قرآنية في القرآن

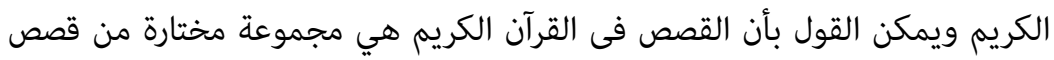
الأمم السابقة التي تم السعي منها لتحقيق غرض خاص بحيث أن الأهداف والآثار

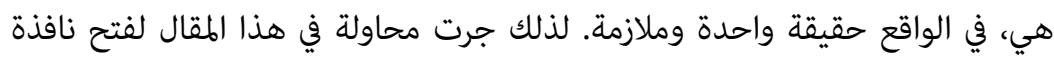
جديدة على بنية القصص القرآنية وأسلوبها وقد تم ذلك بحسب آراء آمهاء المفسرين الشيعة وتم البحث بهدف تحليل الأبعاد المختلفة للقصص القرآنية واستكشاف أهدافها وبنيتها وطرق معالجتها. يهدف هذا البحث إلى دراسة وتحليل عناصر القصص القرآنية بأسلوب خاص في تصوير القصص القرآنية بطريقة وصفية تحليلية. 
تظهر نتائج البحث أن ممارسة سرد الروايات (الرواية) في القصص القرآنية يكن

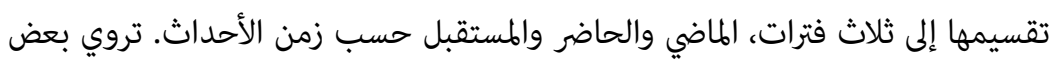
القصص القرآنية قصص الأنبياء والأمم السابقة من أجل تهدئة قلب الرسول وهداية المؤمنين الصادقين وتتضمن نصائح تتوجه نحو المخاطبين فى زمن الرواية (الأمم

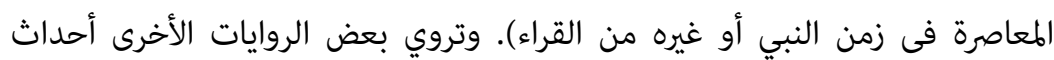
الحاضر أو المستقبل القريب لعصر النبي وتصف قصص وأحدي أحداث حياة النبي مع قومه.

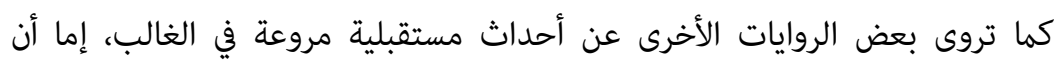
تحدث قريبًا جدًا ويشاهدها عن كثب أهل عصر النبي (على سبيل المثال، خبر الفتح الروماني للإيرانيين) أو أحداث قد تحدث في المستقبل البعيد. إن بنية القصص القرآنية

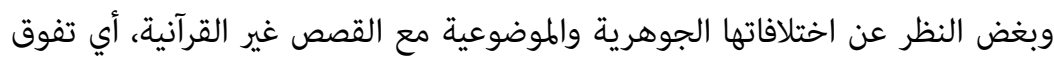

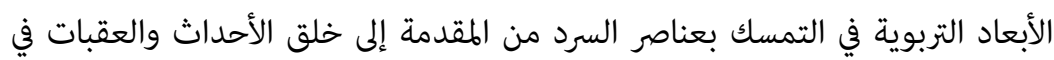

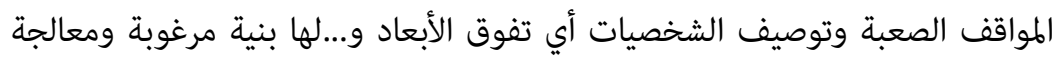
خاصة بحيث من خلال الاستفادة من نسيج فني وبنية قوية وممتعة، يتم تقديم الرواية بشكل صادق وبأجمل طريقة.

\section{الكلمات الدليلة: القصص القرآنية، المفسرون الشيعة، المفاهيم، دراسة}

\section{بنية القصص القرآنية وأسلوبها.}

تعتبر طريقة سرد الروايات أداة عالمية تستخدم اكتساب المعرفة وكذلك التعبير عن المعرفة. وبهذا المعنى، فإن القصص القرآنية هي نوع من اكتساب المعرفة ودراسة بنيتها ووظائفها هي

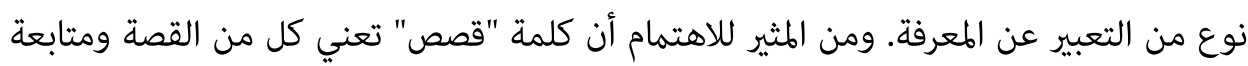
القصة، وكذلك طريقة سرد القصة. يمكن دراسة الرواية من منظورين. أحدهما الرواية كنوع أدبي والآخر الرواية كتركيب لغوي. كما يقال، فإن أي شيء يدل على سرد القصة بأي شكل ومضمون يسمى الرواية. في الواقع، هذا هو القاسم المشترك بين جميع الروايات في القصة التي يتم سردها. 
من وجهة نظر لغوية، تعتبر الرواية خطاب يتكون من مجموعة من الأشكال أو القواعد اللغوية، والنظرية السردية أو القواعد النحوية هي الدراسة المنهجية لبنية الأجزاء المكونة للرواية ؛ لذلك فإن كل ما يروى أو يسرد قصة يسمى بالرواية، ورواية الأحداث تعني أن الروايات تُروى في لئي لحظات وأوقات متتالية ومتواصلة. وهذا التعريف يثير موضوعًا آخر: ما المقصود بفعل الرواية/ السرد (narration) ؟ يشير ريمون كينان إلى أن: "كلمة سرد الرواية تشير إلى ا. عملية الاتصال التي يرسل فيها المرسل الرواية في شكل رسالة إلى المتلقي أى المخاطب. "الطبيعة اللفظية للوسيلة الإعلامية التي تنقل الرسالة." بالطبع، لا يقتصر فعل الرواية أو سردها على هذين الجانبين. باختصار، يشير سرد الرواية إلى الطريقة التي تُروى بها القصة (بما في ذلك الأحداث والأشخاص والكائنات) على مستوى نص الرواية، والتي يعتبرها بعض علماء سرد الروايات بأنها تطابق التصميم(الحبكة) النهائية للموضوع. الآن، ما هى رواية القصص؟ تعتبر رواية القصص

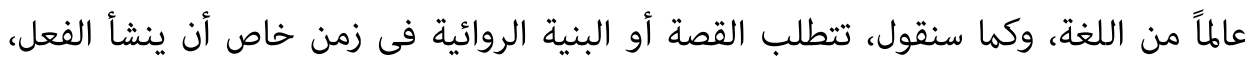
وينشأ الفعل أيضاً من الأحداث، أي أنها تتغير من حالة إلى أخرى. وسيستغرق هذا التغيير زمن. يخلق التسلسل المستمر للحالات تسلسل الأحداث، ورواية القصة تتمحور فى تسلسل الأحداث في محور الوقت. الأحداث، إما حسب ترتيبًا زمنيًا أو ترتيباً يتضمن السببية ، أو كليهما، تتحد لتشكل التسلسلات: إن التسلسلات الدقيقة والتسلسلات الواسعة والرواية بأكملها مصنوعة أيضًا من الترابط بين التسلسلات الواسعة. تمت مناقشة دراسة النظام الذي يحكم رواية القصص في مجال النظرية وقواعد الرواية أو علم السرد الروائي. يكن تقسيم ممارسة الرواية (سرد الروايات) في القصص القرآنية إلى ثلاث فترات، الماضي والحاضر والمستقبل، وفقًا لوقت الأحداث. تروي القصص القرآنية يمكن تقسيمها إلى ثلاث فترات، الماضي والحاضر والطستقبل حسب زمن الأحداث. تروي بعض القصص القرآنية قصص الأنبياء والأمم السابقة من أجل تهدئة قلب الرسول وهداية المؤمنين الصادقين وتتضمن نصائح تتوجه نحو المخاطبين فى زمن الرواية (الأمم المعاصرة فى زمن النبي أو غيره من القراء). وتروي بعض الروايات الأخرى أحداث الحاضر أو المستقبل القريب لعصر النبي وتصف قصص أحص وأحداث حياة النبي مع قومه. كما تروى بعض الروايات الأخرى عن أحداث مستقبلية مروعة في الغالب، 
إما أن تحدث قريبًا جدًا ويشاهدها عن كثب أهل عصر النبي (على سبيل المثال، خبر الفتح الروماني للإيرانيين) أو أحداث قد تحدث في المستقبل البعيد وتشير غالباً إلى الأحداث المروعة ليوم القيامة. يصور القرآن هذا المستقبل ببراعة وفعالية (في السور المكية) بحيث لا يكون حدوثها في أي لحظة بعيدًا. من وجهة نظر سرد الروايات، فإن طريقة رواية القصص هي دالة لوقت وقوع الأحداث وتنقسم إلى أربعة أنواع: ا. حدثت القصة وأحداثها تماماً في الماضي ؛ ثم تُروى القصة للآخرين (السرد التالي أو اللاحق). معظم أحداث وقصص الأنبياء تت روايتها على

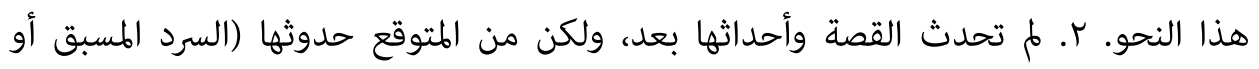
السابق). معظم هذه القصص عبارة عن سور قصيرة مكية وتصور الأحداث المتعلقة بيوم القيامة. هذه القصص ليست لفظية ولكنها تستند أساسًا إلى الصورة والتوضيح. الحوادث والأحداث، على عكس الأنواع الأخرى من الروايات، ليس لها مسار خطي أو غير خطي وتتبع نوعًا من حالات اللا مكان واللا زمان ؛ كما تتطلب طبيعة مثل هذه الأحداث. س. الروايات التي تتكون في نفس وقت الرواية (السرد المتزامن). ومن بينها أحداث حياة الرسول وبصفة عامة أحداث سيرته. ع. يتم سرد الرواية والأحداث بالتناوب وواحدة تلو الأخرى (السرد المزود). ومن الأمثلة على هذه الرواية قصة ولادة مريم ويحيى وعيسى، التي وردت بالتناوب في سورة آل عمران. تشجع هذه الطريقة من رواية القصص أسلوب "القصة في القصة". بالطبع، يبدو أن السرد اللاحق هو النمط السائد في القصص القرآنية. التصوير هو أحد الأساليب الفنية الفعالة في إحداث التعاليم والرسائل الدينية للقرآن الكريم، ويعتبر الأداة الرئيسية لأسلوب القرآن الكريم. يعبر القرآن عن المعاني العقلية والحالات الداخلية والأحداث الملموسة بالصور الحسية والخيالية ويمنح الصور الحياة والحركة. ونتيجة لذلك، تتحول المعاني العقلية إلى حركة، وتتحول الحالات الداخلية إلى لوحات ومناظر طبيعية. يكن رؤية قصص أنبياء مثل موسى وإبراهيم ونوح وهود وصالح ولوط وشعيب بوضوح في رواية هذه القصص. بعد هذا، نحاول في هذا البحث تحليل الأساليب الروائية وأقوال القصص القرآنية باستخدام المنهج الوصفي التحليلي. وعليه ننوي في هذا المقال دراسة وتحليل أساليب ورواية القصص القرآنية بحسب آراء المفسرين الشيعة والإجابة على الأسئلة. 


\section{أسئلة البحث}

() ما الفرق بين القصص القرآنية والقصص العادية؟ r) ما هي خصائص الرواية وسرد الرواية في قصص القرآن؟ r) كيف تبلور عنصر الزمان والهكان في القصص القرآنية؟

\section{فرضيات البحث}

(1) تختلف الحالات بين القصص القرآنية والقصص البشرية مع بعض الحالات مثل القصص القصيرة والطويلة والأساطير والأفلام والمسرح من عدة نواحٍ وطريقة ومحتوى وغرض.

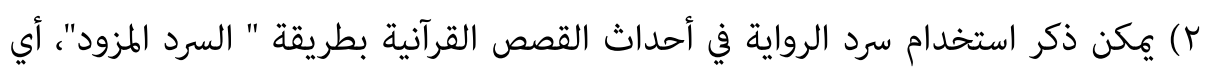
بالتناوب وسرد رواية تلى الأخرة. يسمى هذا النوع من رواية القصص "قصة في القصة".

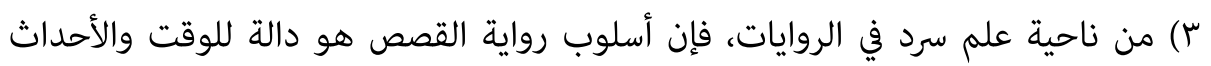

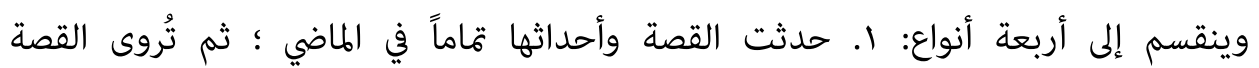
للآخرين.معظم أحداث وقصص الأنبياء تت روايتها على هذا النحو. الثانى. مل تحدث القصة وأحداثها بعل، ولكن من المتوقع حدوثها.معظم هذه القصص عبارة عن سور قصيرة مكية وتصور الأحداث المتعلقة بيوم القيامة. هذه القصص ليست لفظية ولكنها تستند أساسًا إلى هنى الصورة والتوضيح. الحوادث والأحداث، على عكس الأنواع الأخرى من الروايات، ليس لها مسار خطي أو غير خطي وتتبع نوعًا من حالات اللا مكان واللا زمان ؛ كما تتطلب طبيعة مثل هذه الأحداث.

\section{منهج البحث}

تم في هذا البحث دراسة وتحليل عناصر القصص القرآنية بأسلوب خاص في توضيح القصص القرآنية بالطريقة الوصفية التحليلية، وبالاعتماد على المصادر المكتبية والمنهج التحليلي. ومنهج البحث في هذه الدراسة هو المقارنة وتحليل الروايات والدراسات النصية. 


\section{خلفية البحث}

بداية الاهتمام بالقصص والحكايات القرآنية بشكل علمي متماسك من سيد قطب وكتاب "التصوير الفنى ". بالإضافة إلى هذا الكتاب، تت كتابة مقالات وأطروحات في هذا المجال في

$$
\text { السنوات الأخيرة. }
$$

مقال "تحليل بنية رواية أصحاب الكهف في القرآن الكريم": في هذا المقال، تم النظر فقط في اسلوب سورة الكهف، وتم إيلاء اهتمام أقل لوجهة نظر المعلقين. إن مقال "التحليل السردي لسورة نوح (ع) بناءً على آراء رولان بارت وجيرارد جينيت": كماء يتضح من عنوان المقال، فإن آراء المعلقين مل تؤخذ بعين الاعتبار هنا أيضًا. كما أن مقال "تصنيف فن التعليق في قصص القرآن الكريم": هذه المقالة أيضًا لا تولي اهتماما لبنية المقال وآراء المعلقين. أطروحة بعنوان "هيكل الحوارات الخيالية لقصص القرآن الكريم" تتناول هذه الرسالة بنية القصص القرآنية مع التركيز على عنصر الحوار. الغرض من هذه المراجعة هو الإجابة على سؤالين عامين. ما الفرق بين القصص العرفية والبشرية وقصص الوحي القرآني؟ ما هي بنية القصص القرآنية؟ للإجابة على هذه الأسئلة من منظور الأدب والفن والتفسير، كان من الضروري التعامل مع خطاب النقد الأدبي في سياق البنيوية والسرد، خلال ذلك، يجب تسمية المفكرين المهمين في هذا المجال في الغرب والعالم الإسلامي وتحليل مفاهيمهم المهمة. رسالة بعنوان "التركيب المسرحي لقصص النبي موسى (ع) في القرآن" العنوان العملي: سلامان

حيث في هذا البحث، من أجل دراسة هيكل وطريقة السرد في القرآن الكريم، نعتزم الرجوع إلى التفسيرات الشيعية ووفقاً لمقاصد نزول القرآن وعلاقة الآيات والسور ومدى ملاءمتها، فلنراجع آراء المفسرين في هذا الصدد.، قدمنا أيضًا أوجه الاختلاف والتشابه بين قصص القرآن وقصص اليوم. قصص القرآن لها خلفية وتوصيف وأحداث ثانوية وأساسية في القصة ونتائجها وأنواعها وزاوية الرؤية في القصة. 


\section{الأساليب القرآنية في رواية القصص القرآنية}

انطلاقا من أن الإنسان له أبعاد مختلفة، فإن طرقه في التوجيه متنوعة أيضًا ولها أبعاد مختلفة. وعليه، فإن الكتاب الذي تم إعداده كدليل كامل للإنسان يجب أن يستفيد من جميع جوانب الإنسانية (محمدى اشتهارى، 1/را ش: r) ؛ لذلك، لاستخدام القصص القرآنية بطريقة منهجية، اعتمد المفكرون طريقتين في هذا الصدد: أ) المنهج التاريخي ب) المنهج المتسلسل. أ) المنهج التاريخي: ومن الأدلة المؤثرة في معنى آيات القرآن ولفهم معاني الآيات من الضروري الانتباه إليها هو فضاء نزول الآيات. من القرائن الأخرى هى الخصائص الخارجية

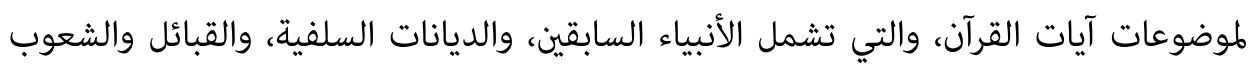
السابقة، وغيرها من الأمور التاريخية التي تتحدث عنها آيات القرآن. ومن الواضح أن أحد سبل الإدراك من هذين النوعين هي الأخبار التاريخية فى زمن نزول القرآن والفترة التي سبقته (رجبي وآخرون، זوسا ش: 1 1 ).

ب) المنهج المتسلسل: يعتبر الأسلوب آخر هو الترتيب القرآني، وفي هذه الطريقة يشرح المفسر مجموعة الآيات التي نزلت في مجال القصص حسب ترتيب الآيات .في هذه الطريقة، يتم فحص القصص حسب ترتيب نزول السور والآيات والغرض الرئيسي منه وترتيب نزولها. ب- اهداف القصص القرآنية ليس الهدف من نزول القرآن رواية القصص والتسلية، ولكنه استخدم جاذبية القصة، التي

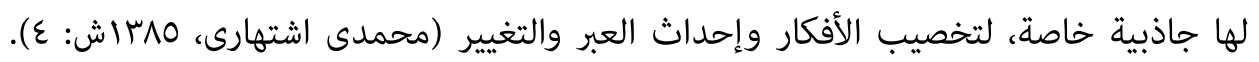
الهدف الآخر من القصة هو إثبات الوحيظ والرسالة. النبى محمد(ص) مل يكن كاتبا و لا قارى ء، و مل يحضر اجتماعات العلماءاليهود و المسيحيين.و هذه القصص مذكورة فى القرآن بحيث يتم

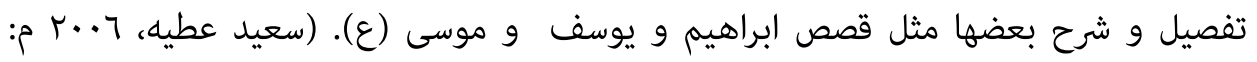

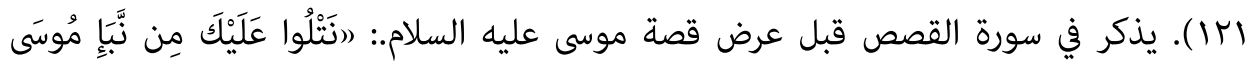

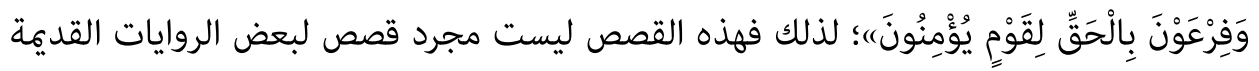
التي تسلى المستمعين وتتجاهل حكاياتهم ونصائحهم، بل هي سيرة ذاتية لتاريخ الدعوة الدينية، وكيفية تدفقها بين الناس منذ بداية الخلق. الحكمة من وراء هذه القصص متنوعة: 


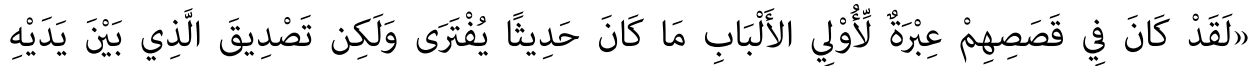

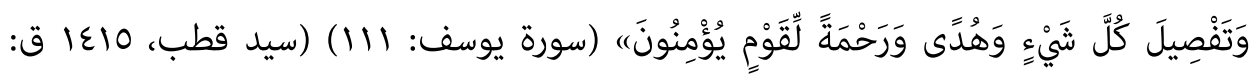
11) (1). الغرض من القصة القرآنية إثبات الوحي والرسالة المذكورين في بداية بعض السور النصية.

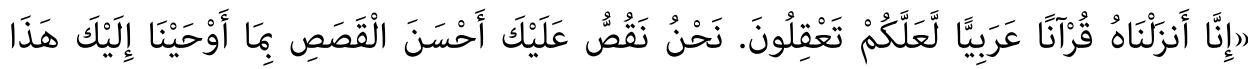

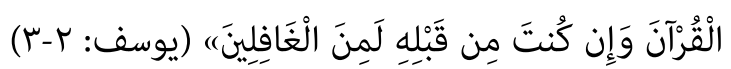

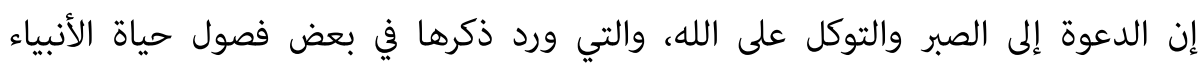
السابقين أو ذويهم، مذكورة بهدف تهدئتهم وتقويتهم في المشقات والمشقات من أجل تهدئة وتقوية القلب الطيب للرسول الكريم (ص). التبرير والتوجيه، وتشجيع وحدانية المعارضة، وترهيبها، ونصرة الرسول (ص)، ومساعدته بالمعجزات، والتعبير عن وحدة دعوة الأنبياء، والتعبير

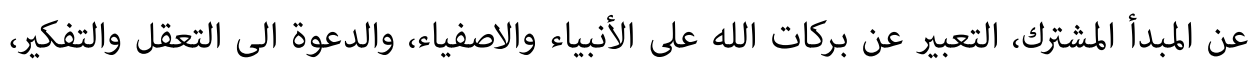
إلخ.، (سيد قطب: المصدر نفسه). والغرض الآخر من القصة هو بيان أن جميع الأديان هي من الن النياء عند الله من زمن نوح إلى زمن محمد (صلى الله عليه وسلم) وأن جميع المؤمنين أمة واحدة والله رب الجميع وكم عدد قصص الأنبياء التي رويت بطريقة واحدة وعرضت بشكل خاص

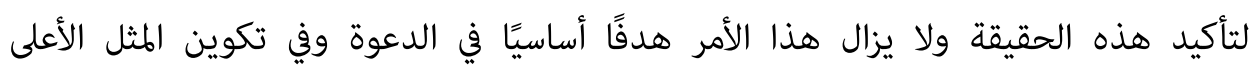
الإسلامي. الغرض الآخر من القصة هو الاعتراف بالبشارات والمخاوف، بالإضافة إلى تقديم مثال

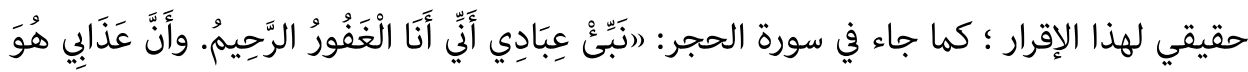

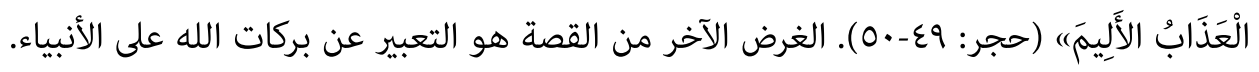

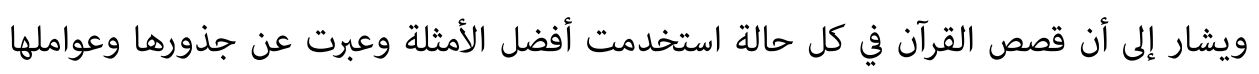

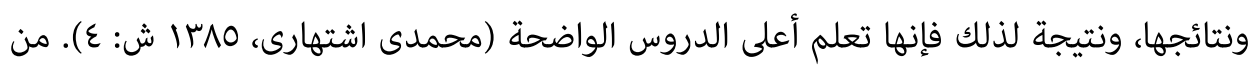
أهم أهداف القرآن رواية القصص والنصائح والدروس، ويمكن تقييم هذا الهدف في إطار الغرض آنهائ الأساسي من القرآن وهو إرشاد الناس. والغرض الآخر هو أن العديد من القصص غير معروفة

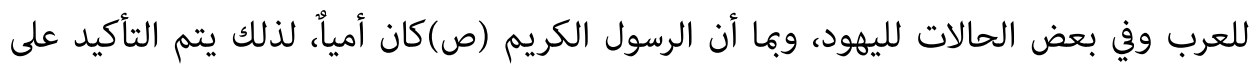

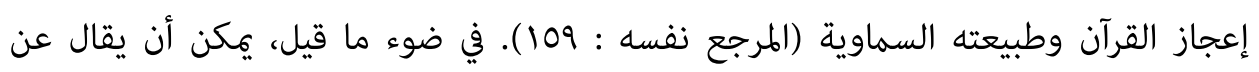
مقاصد رواية القرآن: إن الغرض الأساسي من القرآن في سرد قصصه هو ترير الإنسان في الممرات 
المظلمة وإيصاله إلى أرض التنوير. والتوجيه. سعياً وراء هذا الهدف الرئيسي، تتطلب المناسبة

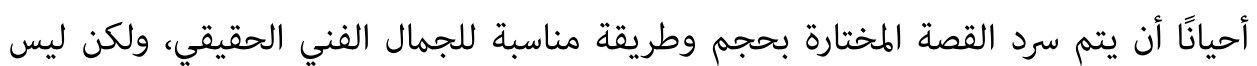
على أساس الخيال ورواية القصص، ولكن على أساس المبادرة الفنية والإبداع في كيفية التقرير

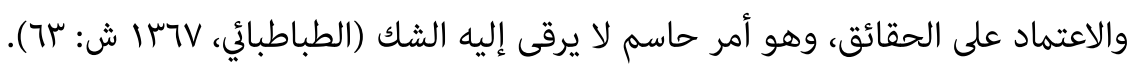

\section{ع- منهج القرآن حول كيفية بدء القصة}

نظرا لتعدد هذه الموضوعات والمفاهيم، فقد تم استخدام طرق تعبيرية وأدوات فنية مختلفة، ويمكن ملاحظة ذلك في السور القصيرة والطويلة وفي الآيات المترابطة أو في الموضوعات

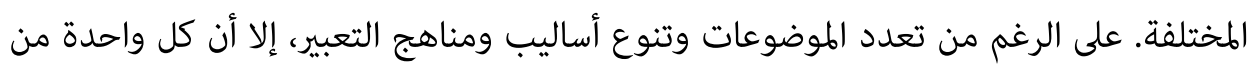
هذه الموضوعات ليست محددة. بدلاً من ذلك، للقرآن كرامة وطريقة فريدة في التعبير عن الموضوعات، بحيث لم يتم إثارة أي موضوع في إحدى صفحات القرآن بشكل مستقل ومنفصل عن الموضوعات الأخرى. وبدلاً من ذلك، فقد أصبحت الموضوعات متشابكة للغاية بحيث أصبح الأمر كما لو أن القرآن الكريم لا يريد عن قصد أن ينتبه قارئه إلى تلك الموضوعات في حد ذاتها، ولكنه وضع كل موضوع في إطار منسق يتعلق بهدفه الرئيسي .يعتبر سرد الأحداث بمنهج موجز ومفصل من أهم سمات القصص القرآنية. في طريقة سرد القصص في القرآن، مثل طرق سرد القصص البشرية الشائعة التي لها ترتيب معين من حيث التقدم والتأخر وتتبع الترتيب الزمني الطولي والخطي، لا يوجد تقريبًا ترتيب خاص وتسلسل زمني وليس صحيحًا أن القرآن يصف ترف جميع الأحداث والتفاصيل بالتفصيل وبشكل منهجي فيما يتعلق بالنبي أو جماعة عرقية. بل إنه يروي ما قصده الله لتلك القصة. وهكذا، يستشهد القرآن الكريم أحيانًا بالمختصر قبل وصفه بالتفصيل. وخير مثال على هذا الأسلوب يظهر في قصة اصحاب الكهف (سيد قطب،10 ق: اعا إ VVV ع (I).قصة أصحاب الكهف فيها هدى هؤلاء الصحابة من الله وإيمانهم وجهاد الكفار، وملجأهم في الكهف، ومعجزة بقائهم بعون الله، وقيامتهم، ولقاءهم بالناس وإيضاح الحقيقة

$$
\text { والتعبير عن الخلاف بين الكفار والنبي (ص) (معمورى، بوسا ش: • •17). }
$$

ميزة أخرى للقصة القرآنية هي أنه في بعض الأحيان قبل التطرق إلى تفاصيل القصة، يتم ذكر النتيجة (نفسه) وهناك طريقة أخرى لرواية القصص في القرآن وهي أن القصة مقسمة إلى 
أجزاء وحبكات مختلفة، وبعض المشاهد غير المفهومة تبقى غير مفهومة لإعطاء الجمهور فرصة لتوضيح القصة ومقارنتها ودائًا ما يبقي القارئ في سعي وراء المشاهد ويستخدم قوة تفكيره

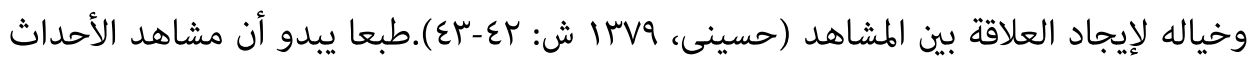
في قصص القرآن تتقدم وتتأخر حسب درجة الأهمية. والغرض من هذا الأسلوب في القصص القرآنية، وأبرز مثال على ذلك قصة النبي يوسف (عليه السلام)، هو الحفاظ على أصالة رسالة القصة. أحيانًا في بعض قصص القرآن تنزل نتيجة القصة في بداية القصة لسبب ما، وأحيانًا على لى

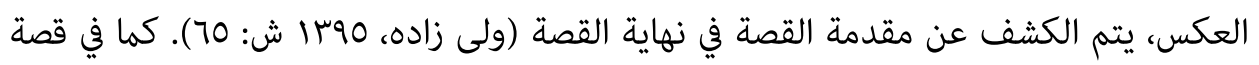
البقرة الإسرائيلية في سورة البقرة (الآيات: ب-7)، تكون مقدمة القصة في نهايتها ؛ لأن ترتيب ذبح البقرة أولاً، وتجادل الناس مع موسى على اختيار تلك البقرة، وأخيراً جاء: ضع بعض أجزاء من

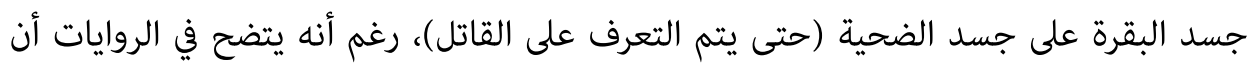
الشاب الأول قتل وأن القاتل الذي كان من أهل الضحية ألقى جسد الشاب على طريق أحد أفضل قبائل إسرائيل وجاء إلى موسى (عليه السلام) وطلب ثار الدم.يقول العلامة طباطبائي في "الميزان" إن السبب في ذلك هو إثارة فضول القارئ، لأنه في استجابة لطلب التعرف على القاتل يقول بذبح بقرة. ربما كانت عبادة العجل والبقر لا تزال متأصلة في نفوس الناس.يبدو أنه قد تم

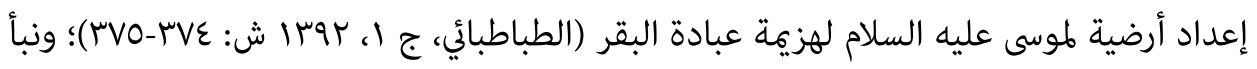
ذبح بقرة أهم بالنسبة لهم من قطع رأس إنسان عادي. وبالتالي، فإن رسالة القصص القرآنية ليست بالضرورة في نهاية القصص، وربما في الجزء المهم من القصة وفي لغة الأبطال، فهي تنقل رسالتها الإرشادية بطريقة ماهرة وأصلية وحديثة للمخاط. تبدأ بعض القصص القرآنية أيضًا بمقدمة يمكن تقديمها بطرق مختلفة بناءً على أهداف محددة. في بعض الأحيان تكون المقدمة في شكل استجواب، مما يمنح القارئ قوة دفع وحافزًا لمتابعة القصة وبعض المقدمات عبارة عن ملخص للقصة، ثم يخوض في التفاصيل. القرآن في سورة الأعراف بهذه المقدمة، لقد مكناكم فى الارض وجعلنا لكم فيها معايش قليلاً ما تشكرون، بدأ قصة خلق البشر وطاعتهم على الأرض وتناول هذه الطاعة بالتفصيل خلال خمس عشرة آية (الآيات (I-1) وقد تناولت هذه الطاعة بالتفصيل وهي تفصيل موجز ورد ذكره في الآية السابقة (الطباطبائي، ج I، إIVV ش)، لذلك فإن 
الغرض من القرآن في ذكر أحداث الأمم السابقة والأنبياء العظام هو العقاب والإرشاد والاستفادة من الأحداث التاريخية. لذلك، مناسبة لهذا الغرض، شتتهم في إصحاحات مختلفة وعبّر عنها وفقًا لأحداث الوحي.

\section{0- القصص الطويلة}

في الأشكال المختلفة للقصص القرآنية، تستند فوائد شكل القصة إلى النصيحة والدرس

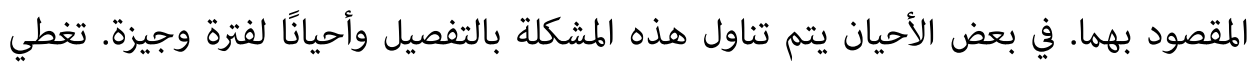
القصص الطويلة العديد من جوانب حياة الشخصية الأولى. قصة النبي موسى عليه السلام هي أطول قصة في القرآن الكريم، وتشمل: الولادة، وفترة النمو، والحياة قبل البعثة، وبعدهاه التهائ في النبوة والرسالة، والأحداث التي وقعت على يد شعب إسرائيل، وطرق دعوة ذلك الإمام. أو قصة النبى إبراهيم (ع) والنبى سلمان (ع) والنبى يوسف (ع) التي لا تتناول موضوع ولادة الشخصيات بشكل مباشر وتقتصر على فترة الحياة بعد الرسالة وأحداثها ؛ ولكن الأكيد أن القصص الطويلة تصور المشاعر والعجائب التي ظهرت وتجلت في البشر بحالات مثل الغضب والرضا والصداقة والتضحية بالنفس والحماس بطريقة تشمل جميع أنواع النصائح.

\section{7- النبي موسى (ع)}

ذكرت قصة موسى (ع)في حوالي ثلاثين نقطة من القرآن الكريم. في السور: اعلى، فجر، اعراف، فرقان، طه، شعرا، ثل، قصص، اسراء، يونس، حود، غافر، فصلت، زخرف، ذاريات، كهف، ابراهيم (في نقطتين وأيضاً في سور بقره، نسا، مائده ونازعات. ويرد في بعضها بالتفصيل وفي البعض الآخر ملخص لحياة ذلك الإمام وأحداثه.. في سرد قصة النبي موسى (ع)، يتابع القرآن الكريم بالتفصيل الأهداف التي تتهاشى مع المقاصد السامية لنزول القرآن، وتشمل ما يلي: ا - ذكر ظروف ما قبل ولادة النبي موسى وقتل أبنائه بأمر فرعون وبشارة للمظلومين وورثة

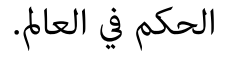

r- ولادة موسى وخوف أمه من فرعون بسبب ولادته، أمر الله أن يرضعه وعند القلق على

$$
\text { حياته رمى موسى في البحر ووعده بإعادته وإعلان رسالته. }
$$


بـ- قصة أخذ موسى من النهر على يد جنود فرعون، نُقل موسى إلى بيت فرعون، ونشأ موسى معه بناءً على طلب من زوجته، نفس الشخص الذي قرر، بالرغم من الحذر الشديد، القضاء على

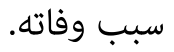

ع- ذكر هموم والدة موسى بعد انفصالها عن طفلها ومتابعة طلب موسى وعملية إرضاعه من قبل والدته للحكمة والقدر الإلهي. 0- تصوير طفولة النبي موسى (ع) بين ذراعي أمه، بلغ موسى النمو والكمال وأعطاه الله العلم والحكمة وأعطي مكانة وصل إلى مرتبة الفضيلة، وقصة الشجار بين رجلين ومساعدة موسى عليه السلام وأخيراً قتل أحدهم وندم النبي موسى عليه السلام.. 7- التعبير عن الحالة النفسية للنبي موسى (ع) بعد القتل غير العمد للمصري الذي جعله يخشى الأحداث المؤسفة التالية، وإبلاغ شخص نصح النبي موسى (ع) بمؤامرة قومه لقتله مما

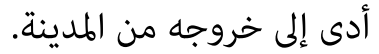
V- قصة إنقاذ موسى ووصوله إلى المدينة المنورة ورؤية بعض الناس الذين اجتمعوا حول الماء وسقوا أغنامهم والمرأتين المنتظرتين ومساعدة موسى على سقاية الغنم وأخيراً صلاة موسى وتضرعه عند الله.

^- انتظار موسى لتلقي الخير والبركات من الله وقصة إحدى الفتيات القادمة بخجل وتواضع ونقل رسالة الأب (النبى شعيب) إلى موسى (ع) لمساعدة بناته وحديث شعيب مع ذلك النبى. 9- حديث النبى شعيب مع ابنته وعرضها على الأب بإستخدام موسى بسبب صفتين جديرتين، القوة والثقة والقبول من قبل شعيب، زواج ابنته من موسى (ع) وإقامته حوالي ثاني أو عشر سنوات فى المدين والجدير بالذكر أن النبي موسى (ع) استقر في المدين، ولكن سواء أقام فيها أو غادرها بعد انقضاء المدة، فسيتم الرد عليه في المشاهد التالية من القصة. • ا- مرحلة جديدة في حياة النبي موسى وهي مرحلة رسالته وعودته إلى مصر ودعوة فرعون والنبلاء هناك إلى التوحيد والتقوى بطرق مختلفة من هذه الفترة من حياة النبي موسى (المدين). مع فرعون بعد النصيحة والحجج المختلفة، فكانت مواجهة موسى مع سحرة فرعون، ونتيجة لتقديم معجزات النبي موسى (ع) والإقرار بها، وعقاب فرعون للسحرة. 
الا تصوير حقبة جديدة في حياة النبي موسى مع بني إسرائيل والعديد من النكبات والمصاعب رغم مساعدة أخيه هارون الذي خصص في القرآن الكريم عدة آيات لإرشاد وتعليم

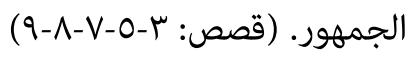

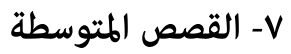

قصص القرآن المتوسطة هي القصص التي تصف جزءًا من حياة البطل، أحيانًا في وقت مبكر من حياته وأحيانًا في الجزء الأخير من حياته. من الواضح أن القصة المتوسطة تتضمن مشاهد أقل من القصص الطويلة، لأن الراوي ومن أجل تحقيق هدفه، والذي غالبًا ما يكون درسًا وإرشادًا، لا يختار سوى الأجزاء التي لها التأثير الأكبر على الجمهور. على سبيل المثال، مشاهد قصة النبي نوح (ع) محدودة في القرآن الكريم أكثر من غيرها من قصص النبي سليمان (ع)

$$
\begin{aligned}
& \text { وموسى (ع) وآدم (ع) وعيسى (ع) وإبراهيم (ع). } \\
& \text { - ا- النبي نوح (ع) }
\end{aligned}
$$

ورد اسم النبي نوح (ع) في ^r سورة من القرآن وفي باع حالة. بدأت هذه القصة من لحظة قيامة الرسول ومل تتناول مولده ونموه ما مل يكن قد وجد مكانًا يستحق قبول الوحي والدعوة

\section{المراحل المختلفة لقصة نوح هي:}

ا - دعوة نوح إلى قومه وأمرهم بعبادة الله الوحيد وعدم الشرك مع الله والأمر بالتقوى

الإلهية علانية وسرية لاتباع الله وطاعة نوح، وهي في الواقع تعتبر طاعة لله.

r- شكوى النبي نوح (ع) بعد فترة طويلة من الدعوة الى الله وإهمال ورفض قومه وحتى كراهيتهم له ودعوته وأخيراً صلاة نوح عند لله ولعنة الظالمين.

ب- دعوة النبي نوح لقومه واستجابتهم، كما يذكر هذا القسم وحيه ويدعو إلى عبادة الله ونبذ شعبه لعدم تفوقه على أنفسهم وأخيرًا استجابة نوح لهم بأسباب واضحة. ع- أمر الله أن يبني نوح السفينة والاستهزاء بأهله رغم وعد نوح بمعاقبتهم. في الواقع، يصف جزء من حياة نوح الطريقة التي دعا بها وتحدث إلى شعبه، والتي تشبه تقريبًا طريقة الأنبياء الآخرين. 
ه- كيفية نزول العذاب على قوم نوح ووضع المؤمنين على السفينة وأخيراً الحوار بين نوح والله وابنه وغرقه مع غيره من الكفار وتجدر الإشارة إلى أنه .

1- - م- القصص القصيرة

وصف الأحداث التي ذكرها القرآن الكريم في مختلف السور باختصار وإيجاز فقط، وغالبًا ما اشتمل على دعوة بعض الأنبياء من شعوبهم ومواقفهم، وأخيرًا المنكرين أو المؤمنين على شكل قصص قصيرة نزلت في القرآن الكريم. من بينها قصة دعوة النبى هود (ع) من قوم عاد والنبى صالح (ع) من قوم ثود والنبى شعيب (ع) ودعوة والنبى لوط (ع) من قومه ونهاية هذه القبائل. وبالطبع فإن بعض القصص القصيرة تكتفي بإشارة موجزة إلى البطل ولا تذكر معلومات عن صفاته الشخصية أو طريقة دعوته، مثل قصص إدريس ويسع وذي الكفل. وبالطبع من القصص القصيرة قصص اصحاب الكهف، وأصحاب الرس، وأصحاب الأخدود، وأصحاب ايكه،

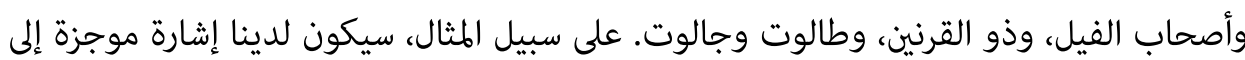
قصتي النبى صالح (ع) في دعوة قوم ثمود وأصحاب الأخدود:

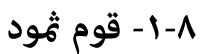

قوم ثود هم من القبائل العربية التي ذكرها القرآن الكريم 7r مرة وتم ذكر قصتهم بإيجاز.

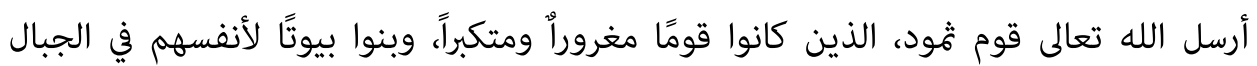
بنحت الحجارة، ليتنبأوا على النبى صالح (ع) من أجل عبادة الله الواحد ولنعهمم من الفساد،

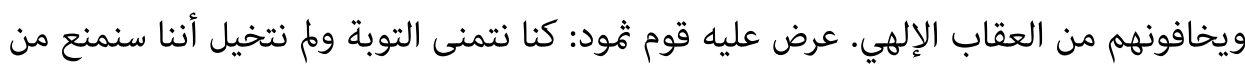
عبادة الآلهة. إذا كنت مخلصًا في دعوتك، فاحضر لنا آيات وإشارات. جلب لهم النبى صالح (ع) ناقة من عند الله وقال: هذه الناقة آية من عند الله. في يوم من الأيام يجب أن تشرب ماء النبع وفي اليوم التالي ؛ لذلك اتركوا الناقة وشأنها حتى ترعى ولا تؤذونها، لكنهم تبعوا الناقة وقال لهم النبى صالح (ع): ابق في بيوتك ثلاثة أيام وانتظر وفي اليوم الرابع حدث زلزال وعاصفة رعدية

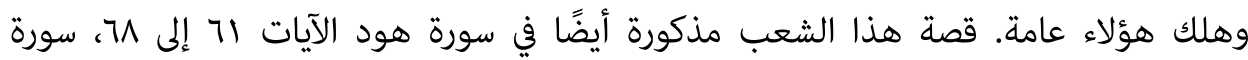

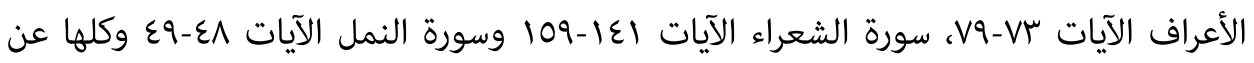


الظالهين والاعتراف بالكفر، وخداع الشيطان، والفساد، وعصيان الله، وإنكار الأنبياء من قبل قوم

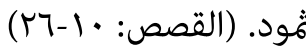

\section{9- مقومات الروايات القرآنية}

تتكون القصص الأدبية والفنية عادة في إطار محدد بعناصر محددة، مثل "الشخصية" و"الحادثة" و"الحركة" و"الوقت" و"المكان" و"الحوار". وبهذه الطريقة يكون عدم وجود أي من هذه العناصر سبباً لنواقص تلك القصة. لكن في القصص القرآنية، العناصر التي طغت عليها "الهدف والرسالة" هي القصة وتستخدم عناصر القصة لدرجة أنها تلعب دورًا في توفير "الهدف

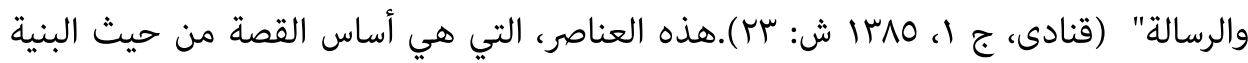
والمحتوى، والقصة مبنية عليها، يمكن تحديدها وتحليلها وتقييمها في القصص الحقيقية للقرآن مع وجود اختلافات في الكمية والنوعية وطريقة التطبيق. لكن عناصر الزمان والكان في القصة تبقى غامضة وغير معلن عنها. سوف يتم فحص كل واحد من هذه المقومات والعناصر:

\section{9- 1 - شخصيات القصة في القرآن:}

من بين عناصر القصة، "شخصية القصة" هي أحد محاور القصة الرئيسية، مع الاختلاف في معظم القصص التاريخية والخيالية، تتمحور "الشخصية" والبطل يأخذها ويتبع القارئ دور البطل أكثر ويولي مزيدًا من الاهتمام لأحداث القصة ويولي بعض الاهتمام لأحداث القصة التي تلعب فيها الشخصية دورًا (قنادى، ج ا، 1/10 ش: عץ). في جميع قصص القرآن، يظهر عنصر الشخصية أو البرسوناج أو أو الكركتير. تمر هذه الشخصيات المسرحية بمراحل مختلفة، وعلى الرغم من أنها أنبياء إلهيون، إلا أنها لا تصبح نوعًا مسرحيًا (غير قابل للتحويل). في الحالات التي لا تؤثر فيها أسماء الأشخاص على نقل رسالة القصة، ولكن تتسبب في انشغال ذهن الجمهور بقضايا فرعية، لا يتم ذكر اسم الشخصية ويتم إيلاء المزيد من الاهتمام إلى جوهر الحادث

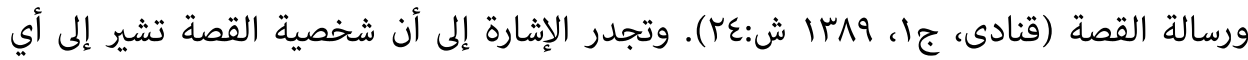

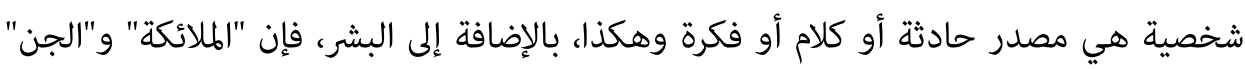

$$
\text { و"الحيوانات" هم أحيانًا شخصيات في القصص القرآنية. }
$$


يعتبر التسلسل الزمني من أهم القضايا المتعلقة بمنظور الوقت. زاوية الرؤية أو المجال الزمني هو في الواقع طريقة الاتصال الزمني في القصة ويتضمن الترتيب الزمني الذي يتم خلطه من قبل المؤلف أحيانًا. "الترتيب هو ترتيب الأحداث السردية على مستوى القصة ومستوى الع النص"."أحيانًا تكون العلاقة الزمنية بين هذين المستويين متطابقة وطبيعية، وأحيانًا يكون هناك اضطراب بين وقت هذين المستويين، وهو ما يسميه جينيه المفارقة فى الوقت".(جينيت، $199 V$ ش:O إع اع):لذلك يُذكر بالترتيب العلاقة بين وقت القصة أو زمن التقويم ووقت السرد، وللوقت

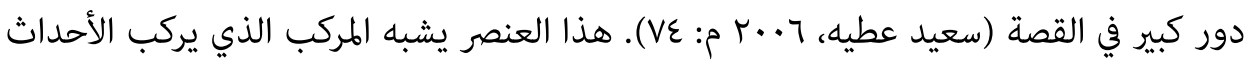
واحدًا تلو الآخر. تصور لحظات "الزمن" مشاهد القصة بشكل مستمر ومتسلسل في ذهن قارئ

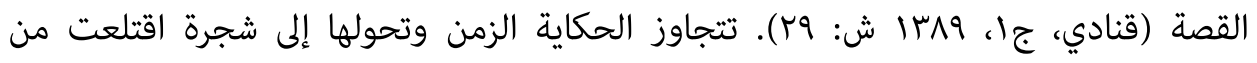
جذورها. القصة الناجحة هي التي تستخدم عنصر الوقت بدقة وأناقة وتجعلها جريئة أو فاتحة حسب المساحة والأسلوب. لا توجد قواعد محددة للاستفادة من الوقت. إنه شعور وروح الفنان

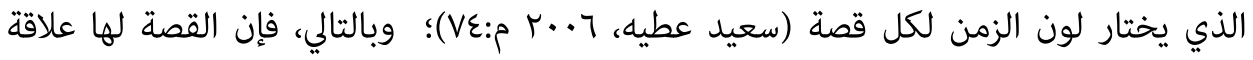
ثنائية الاتجاه مع الوقت لأن وقت القصة هو مزيج من وقت البناء ووقت اللغة الذي تتكون فيه الأفعال. وبهذه الطريقة، فإن وجود الزمن في قصص القرآن هو حضور حي وواع وهادف. على سبيل المثال، انظر إلى قصة يوسف: عندما ألقاه إخوة يوسف في البئر، علموا أن وجوههم تظهر عليها علامات الخسة والخداع والكذب. لذا فإن الوقت المناسب لقول الأخبار للأب اساسى إسى يلعب دورًا رئيسيًا في تحريك القصة إلى الأمام. يختارون الليل حتى لا يواجهوا الآب في النور،

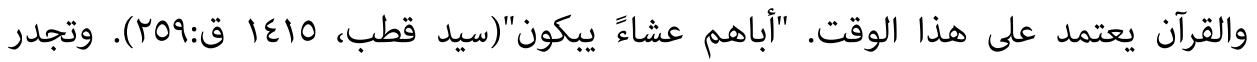
الإشارة إلى أن شخصية القصة هي أي شخصية هي مصدر حدث أو خطاب أو فكر، لذلك بالإضافة إلى البشر، فإن "الملائكة" و"الجن" و"الحيوانات" هم أحيانًا أيضًا شخصيات في القصص

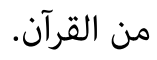

\section{9-ץ- دور المكان في القصص القرآنية}

يعتبر المكان مثل الحاوية التي تجري فيها أحداث القصة. قد لا يكون لموقع الأحداث تأثير خاص على رسالة القصة. لهذا السبب م يذكر القرآن مكان القصة إطلاقا. ما مل يكن لها دور 
خاص في مجرى الأحداث وتعليم الدروس كما في مصر والمدين وفي الطور والأحقاف. مكان القصة لا يقل أهمية عن الوقت، وإذا كان أكثر استقرارًا من الزمن فهو أقل إثارة للجدل. يختلف مكان القصة عن المكان الذي يعرفه القارئ لأن مكان القصة مميز ويوجد له واقع خاص. من خلال الكلمات، يصور مؤلف القصة أماكن في ذهن القارئ تكون أكثر قابلية للتصديق من من من الأماكن الحقيقية المماثلة. قصة الاسراء من الأمثلة الواضحة التي يكون للمكان فيها دور خاص، لأن ذكر "المسجد الحرام" و"المسجد الأقصى" والطسافة بينهما مع العنصر الزمني "الليل" يوضح حدود هذه القصة وبدونها تبقى قصة الصعود في ضباب من الغموض. فلو مل يذكر هذان المسجدان ووقت الليل ما ظهر عند المؤمنين إحساس بالشرف والعظمة (قنادى، جا، وبـا ش:عץ).في نهاية مناقشة عناصر القصة، من الجيد أن نقول أن الحكمة في القصص هي أن العناصر لم يتم تجميعها في موقف واحد ولكن يتم توزيعها ويكون لها التأثير المطلوب في كل موقف. تتدفق قصص القرآن عبر قنوات القصص القصيرة، وليس القصص الطويلة، ومن أسرار القصص أن تستقبل بعض العناصر الشيقة روحها المثيرة.

عدم تآلف المكان في قصة النبي آدم (ع) يعتمد وجود القصة على وجود المكان، وأحيانًا يكون المكان هو سبب وجود القصة.

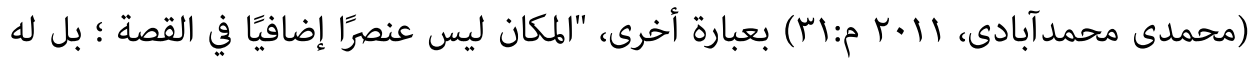
عدة أشكال وموضوعات، والتي قد تكون أحيانًا الهدف النهائي للعمل السرد الروائى". (بحراوى، •199 م:بس). المكان في القصة ؛ إنه ليس مجرد مكان تقع فيه أحداث القصة، ولكنه يشكل موضوع القصة ويسيطر على عناصر أخرى، مما يتسبب في عناصر القصة وربطها ونقل رسالة القصة. توجد في هذه القصة أربعة أماكن ذات خصائص وطبيعة مختلفة: اـ المكان الإلهي، ب-

$$
\text { الجنة، س- الأرض ،ع- النار. }
$$

q-ع- الحبكة:

الحبكة(plot) هي أحد عناصر القصة وتعني "سرد أحداث القصة مع التأكيد على علاقة السبية" ؛ من ناحية، يرتب المؤلف قصته معها، ومن ناحية أخرى، يساعد الجمهور على رؤية أحداث القصة بشكل صحيح. الحبكة "هى ترتيب وتسلسل مجموعة منظمة من الأحداث 
المرتبطة بعلاقة السبب والنتيجة ويتم ترتيبها بنمط وخريطة" (مير صادقى، MM ا ش:ع7). الحبكة مليئة بالقصص مثل قصص الأنبياء والصراع بين قوتين وقطبين غير متجانسين وأحيانًا

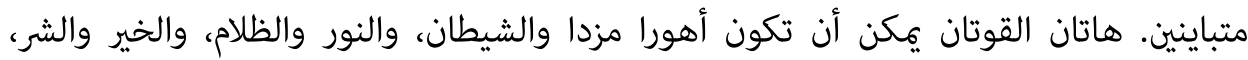
والإيمان والكفر، أو حتى البطل والمناهض للبطل. الصراع بين هاتين القوتين المتعارضتين يضع الأساس للقصة. حبكة قصة إبراهيم هي المواجهة والتوتر بين النبى إبراهيم (ع) من خلال الاعتماد على "القوة الإلهية وشر فرود " والاعتماد على "الكبرياء والوثنية". تدور حبكة القصة حول نفس المحور. يعتقد الكاتب النصي الروسي براب أن "حبكة القصة يجب أن تبدأ جيدًا من حند

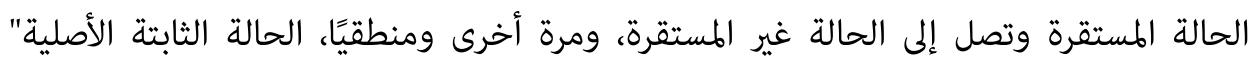
(براب، גדسا ش:" اعI).

\section{• 1 - التركيب القصص القرآنية}

قصص القرآن لها هيكلها الفريد وقد تختلف للوهلة الأولى عما هو مشترك في المعنى المشترك للقصة. على الرغم من أن قصص القرآن تروى حقائق تاريخية لا جدال فيها، فلا يمكن أبدًا أن

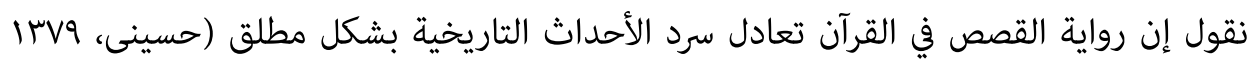
ش:بr). فإن سرد القصص في القرآن ليس في الغالب طريقة تقليدية لرواية القصص، ولكن بغض النظر عن الترتيب والتركيب والسرد الخطي للقصص، يتم سردها بأسلوبها الفريد بالإضافة إلى لى الآيات والسير الذاتية لأسلافها حتى يتعلم الكتاب من حياتهم ويسلكوا الطريق الذي يتعين

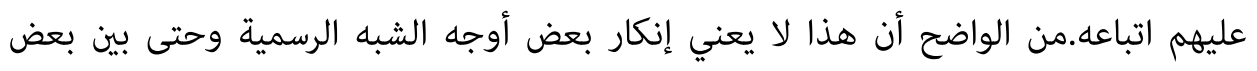

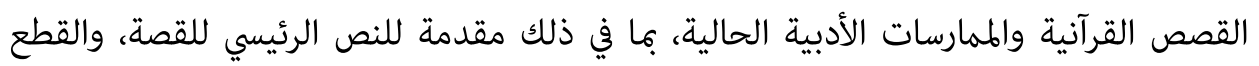
الفنية بين المشاهد، والتوضيح الفني، والشخصية والتوصيف، والمشهد والتدريج والصراعات والمحادثات والحالات الأخرى التي يمكن أن تكون بحد ذاتها أساسًا لكتابات منفصلة من أجل

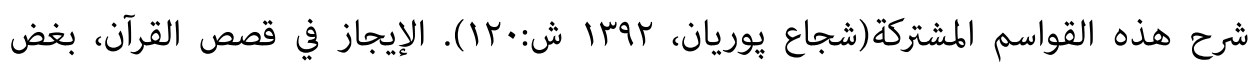
النظر عن الجانب الخطابي والمعجمي، يتعلق أكثر باختيار المشاهد المؤثرة في عملية سرد الحكايات بعناية وترك الأجزاء الزائدة، وهذا عمل فعال للغاية في التجميع النهائي لعمل فني. يمكن رؤية أفضل الأمثلة على هذا التجميع في قصص يوسف ومريم وسليمان وملكة سبأ 
واصحاب الكهف (حسينى، IrV9 ش: عَ). بالطبع، لا تقتصر جمال القرآن غير العادي على عناصره الروحية الغنية وتعاليمه السماوية السامية والمرضية. بل يشمل أيضًا الأساليب الجميلة،

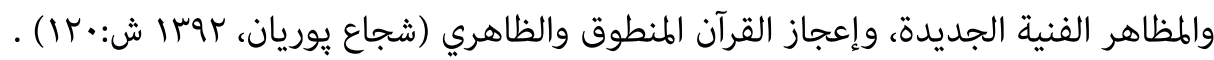

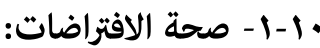

من سمات القصص القرآنية الصدق المطلق والواقعية المطلقة في إعادة سرد القصص التاريخية للأنبياء والأمم السابقة وتعكسها ـالمشاهد التي حدثت في الماضي من التاريخ وشخصيات كانت حاضرة في زمان ومكان محددين بالرغم من وجودهم المستقل وسلوكهم الخاص. لذلك، عندما نقرأ القصص القرآنية، لا يكن الافتراض أن هذه الكلمات لفظها قلم وخيال فنان بلغة شخصية القصة، أو أنه قدم مشاهد إضافية بسبب جاذبيته الفنية(قنادى، جا،

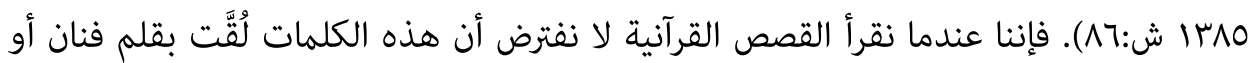
خيال فنان، لذلك فهذه من خصائص القصص القرآنية، إذ تستذكر مشاهد حدثت في التاريخ وشخصيات كانت حاضرة رغم استقلاليتها وسلوكها الخاص وفي زمان ومكان محددين (قنادى،

.(9):

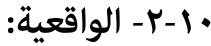

لا بد من الاعتراف بأن القرآن في سرد الوقائع قد تبنى أسلوب انعكاس الحقائق، ولكن ليس

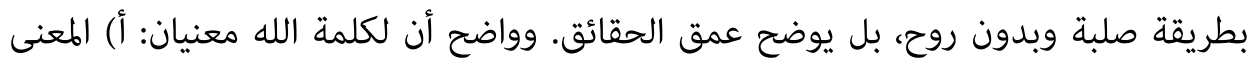

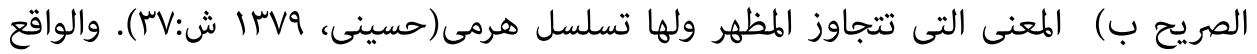
يعني أن القرآن لا يروي إلا الأحداث والحوادث التي وقعت في مجرى التاريخ وحياة الإنسان. ومن السمات الأخرى للقصص القرآنية في قسم العناصر، والتي لا توجد في الخيال البشري إطلاقاً، صحة كلمات وعبارات الشخصيات"بينما آثار اللاواقعية طبيعية في القصص البشرية".

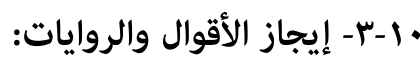
تتميز القصص القرآنية عموماً بالإعجاز والاعتدال ودقة الأحاديث. "معنى مبدأ الإيجاز والاعتدال هو أن القرآن الكريم قد أدخل الشخصيات بأفضل طريقة ممكنة بأقل عدد ممكن من الكلمات"؛وتستخدم أشكال مختلفة من الحوار في قصص القرآن. على الرغم من أن القرآن 
كله إعجازي ومختصر، وأن كل آية من القرآن كانت موضوع تفسيرات وتدويلات عديدة ومختلفة، وبالتالي فقد قت كتابة عدد كبير من تفسيرات القرآن حتى الآن.، لكن هذا الإيجاز

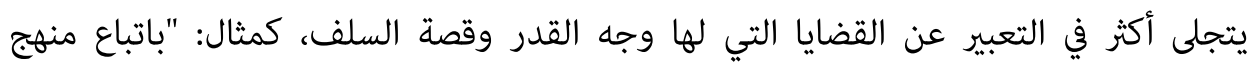
الإيجاز والتأكيد على دور تصوير غير المنطوق وإشراكه في النص، مل يتم تقديم أي شيء عن وجود نوح في السفينة ولكن ذكر الابن، فور انحسار الطوفان، يكفي لإخبارنا عن نوح".

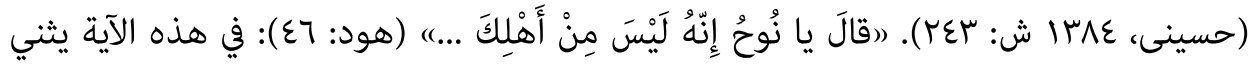

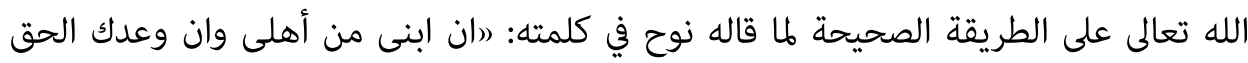

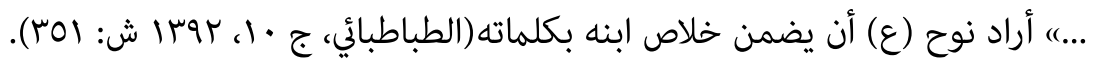

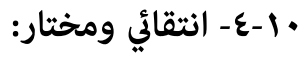
في عرف سرد القصص، يتم سرد الموضوعات المتعلقة بالقصة أو على الأقل الأحداث التي تدور حول الشخصيات الرئيسية في القصة وتنعكس جوانب مختلفة من حياتهم؛ لكن في القرآن، باستثناء حالات قليلة تُذكر فيها قصة فرد أو جماعة عرقية بالتفصيل وبالكامل، في حالات أخرى لا تضيء القصص القرآنية سوى زاوية أو زوايا من القصة بأكملها. إن نهج القرآن في الأحداث والأزمنة الماضية هو نهج انتقائي، ويعبر عن ما يمكن أن يحمل رسالة الدين، ويتضمن خطبة وإرشادًا، ويتضمن دروسًا وإرشادات. وفي رواية حدث يذكر أكثر ما يسهم في تحقيق هذا الهدف وله مكانة خاصة ؛أو في بداية سورة القصص يبدأ القرآن بأكبر قصة للأنبياء وهي قصة موسى (عليه السلام) وفرعون بهذه العبارة: (انتلوا عليك من نبأ موسى وفِرْعَوْنَ بِالْحَقَّ لِقَوْمِ يُوْمِنُونَ)، (قصص:ץ): لقد قرأنا لكم قصة موسى وفرعون بحق، لجماعة تبحث عن الحقيقة وتؤمن (ترجمها العلامة طباطبائي) يعتقد المعلقون أن كلمة "أنا" تدل على التميز (الطباطبائي، ج 17 ال، rوسا ش:V)، أي سوف نقرأ لكم بعض أخبار موسى عليه السلام وهي مزينة بالحق، من أجل شعب يؤمن بآياتنا.

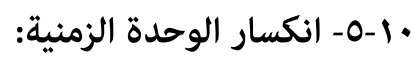
في بعض القصص لا يتم ملاحظة التسلسل الزمني وانكسار الوحدة الزمنية يكون ظاهرًا تمامًا فيها، والسياق يقتضي قطع القصة من الداخل وتغيير بعض المشاهد فيها وعدم مراعاة 
التسلسل، ومن الأمثلة على القصص القرآنية بهذا الهيكل قصة موسى (ع) ومن الأمثلة على القصص القرآنية بهذا الهيكل قصة موسى (عليه السلام) في سورة طه وقصة أصحاب الكهف

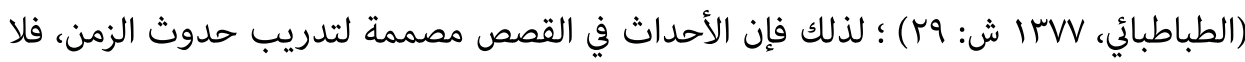
يرى الراوي الأحداث بناءً على رغبة شخصية، ولكن كل شيء يُروى بناءً على وقت الحدث. بالنظر إلى أن حركة الزمن في قصص القرآن هي حركة تقدمية، لأن طبيعة الزمن تتطلب مثل هذه الحركة. يؤدي الخيال في القصص العادية أحيانًا إلى أن يكون وقت الحرده الحركة التراجعية في ارضية صلبة وثابت بلكن اللون الوحيد الذي يمكن رؤيته من حين لآخر في قصص القرآن هو الماضي. وكل الأحداث تجري في الماضي، ولكن السنة والشهر غير محددين، لأن ما يقدم للقصة

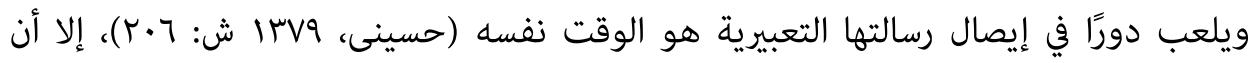
"الخلود والهكان من سمات القصص القرآنية، وهذان العاملان لا يلعبان دورًا مهمًا في تشكيل مجرى الأحداث، ولا نبحث عن آثار للزمان والمكان في القصص، و" لا نجدها، لأن قصص القرآن وحكاياته تتجاوز الزمان والمكان، وهذا هو سبب كون القصص عالمية وأبدية ".

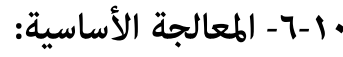
في القصص والأحداث وتسلسل الأحداث تجري بطريقة يكون لكل قصة ومقدمة وبداية وهيكل ونص نهاية حلوة أو مرة، وبشكل عام، تعتمد القصة على الترتيب واللحن الذي يصاحب القارئ ـ في القرآن الكريم، تُعرض أحيانًا الحلقات والمشاهد وأجزاء مختلفة من القصة في فصول مختلفة. "من ناحية أخرى، إذا جمعنا كل الأجزاء الموزعة معًا، نحصل على صورة كاملة لحياة ومصير نوح." هذه الطريقة، التي تظهر عدم التزام القرآن بالسرد الخطي، يكن رؤيتها في معظم قصص القرآن. يوفر القرآن معلومات جوهرية حول قصة واحدة أو قصة محددة في عدة فصول، والتي، إذا قمنا بتجميع مجموعة البيانات المقدمة معًا، تكمل القصة(حسينى، IrV9 ش: 99^و). على الرغم من أن جميع الأبيات الموصوفة تدور حول مغامرة واحدة، إلا أنها تختلف في كل مرة عن سابقاتها. 


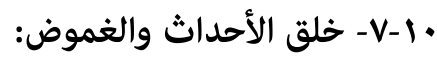

في بناء مسرحية وقصة، يسمى الجزء الذي يستمر من بداية الحدث إلى نقطة الأزمة، أي حل الأحداث. بعبارة أخرى، فإن خلق الأحداث هو موقف صعب يظهر فجأة في بعض الأحيان ويغير البرامج والطرق والمواقف الموجودة (ميرصادقى، rيسا ش: 90ץ). في القصص والطسرحيات والسيناريوهات، يتضمن خلق الأحداث سمات الشخصية وتفاصيل المواقف التي تغير الخط الرئيسي للحبكة وتضع الشخصية الرئيسية في مواجهة قوى أخرى وتخلق عامل الصراع (ميرصادقى، (VT) (NVT)

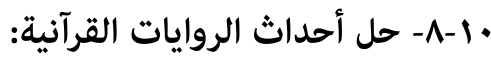

حل الأحداث فى القرآن بجانب النقطة المعاكسة، أي خلق الأحداث، هو الهيكل الرئيسي لجميع الحبكات وبداية ونهاية جوانب التوتر والحركة وديناميكيات القصة. في معظم قصص القرآن، تم حل الأحداث بشكل صحيح. بخصوص الأنبياء والصالحين فالنتيجة مرضية: مثل توبة آدم (ع)، وقبولها، وازدهار نار إبراهيم (ع). بخصوص منكري الأنبياء والكفار والطشركين والشخصيات السلبية، يحدث حل الأحداث مع نزول العذاب وتدميرهم، مثل شعب نوح، وهود، ولوط، وفرعون. أحيانًا بعد حل الأحداث يكون هناك مشهد قصير تنتهي فيه دائرة القصة، هذا المشهد هو نهاية القصة بعض قصص القرآن لها خاتمة وبعضها تنتهى مع حل الأحداث وعند النتيجة|. لكن تجدر الإشارة إلى أن عناصر التصميم ليست منفصلة. وهكذا يبدو أن فلسفة الله وحكمته في كشف القصة هما: إعطاء بعض النصائح (البقرة: اOY)، والتركيز على ماطلب الله

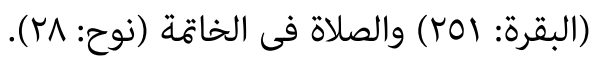

• • (1-9- الحوارات بين القصص:

القرآن، بالإضافة إلى سرد قصة معينة، يأتي أحيانًا بِوضوع منفصلة عن تلك القصة، وهذه ميزة ومنهج للقرآن في القصة. وهذا لا يتعارض مع أسلوب القرآن في رواية القصص (الطباطبائي، مسا شVV

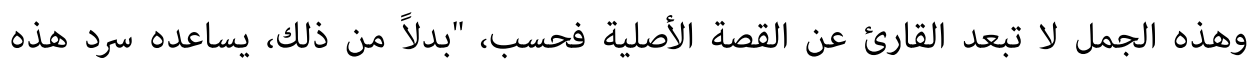
الجمل في الوقت المناسب على فهم رسالة هذه القصص."في سورة آل عمران هكذا تبدأ حكاية 


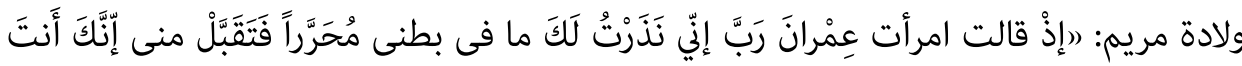

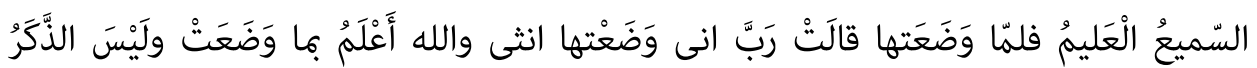

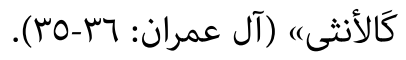

• ا-1-1 الجمع بين عدة قصص في قصة واحدة: إذا وضعنا عدة قصص متشابهة قمامًا لعدة دول في قصة واحدة، فإن الغرض من قصتنا

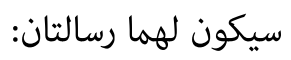
رسالة القصص منفردة ومنفصلة. ب ) الرسالة هي أن هذه القضية لها بعد عام وعالمي وليست خاصة بجنس وزمان ومكان معينين، والمجتمعات اللاحقة ستكون كذلك. (ولى زاده، 901\%ا ش: Ir ) من سمات القصص القرآنية "القصة في القصة"، والتي تعتبر طريقة أخرى لسرد

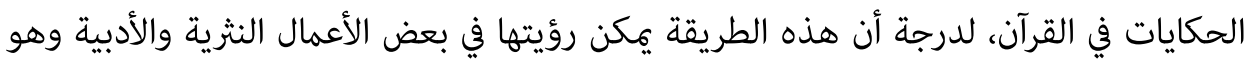

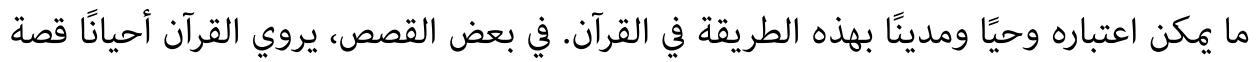

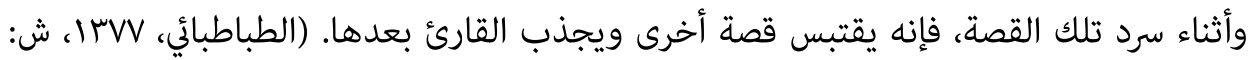

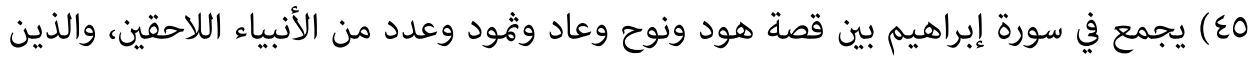

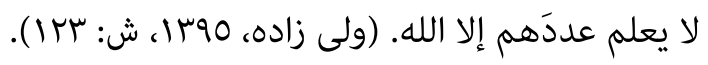

\section{النتيجة}

تعتبر طريقة سرد الروايات أداة عالمية تستخدم اكتساب المعرفة وكذلك التعبير عن المعرفة.

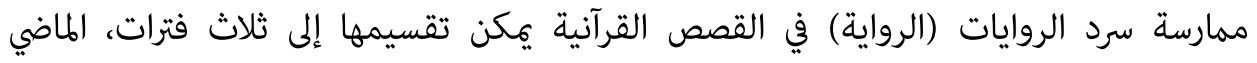
والحاضر والمستقبل حسب زمن الأحداث. تروي بعض القصص القرآنية قصص الأنبياء والأمم السابقة من أجل تهدئة قلب الرسول وهداية المؤمنين الصادقين وتتضمن نصائح تتوجه نحو المدرياء

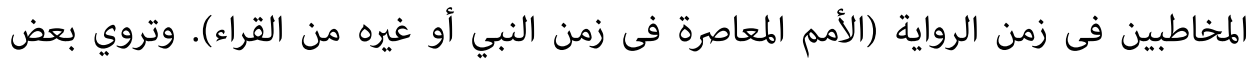

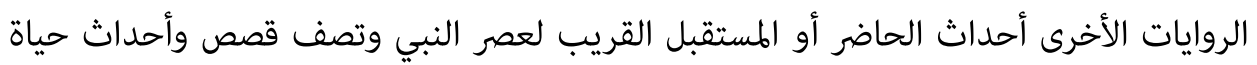

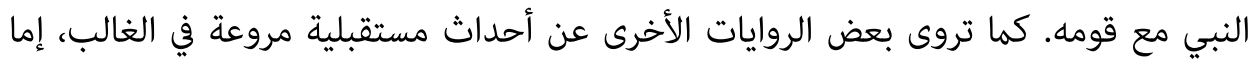

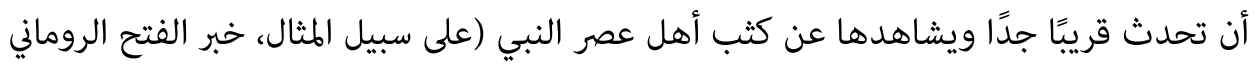


للإيرانيين) أو أحداث قد تحدث في المستقبل البعيد وهى تشير بشكل اساسى إلى الأحداث المروعة ليوم القيامة. يصور القرآن هذا المستقبل ببراعة وفعالية (في السور المكية) بحيث لا يكون حدوثها في أي لحظة بعيدًا. من وجهة نظر سرد الروايات، فإن طريقة رواية القصص هي لهري

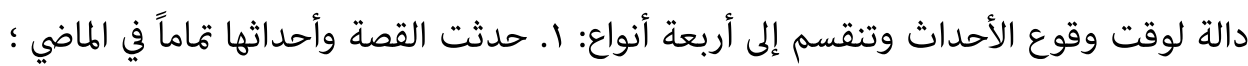
ثم تُروى القصة للآخرين (السرد التالي أو اللاحق). معظم أحداث وقصص الأنبياء تمت روايتها

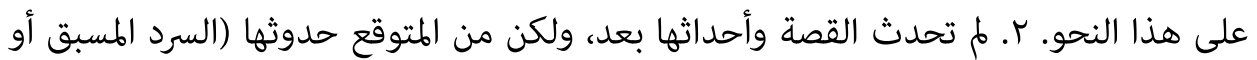
السابق). معظم هذه القصص عبارة عن سور قصيرة مكية وتصور الأحداث المتعلقة بيوم القيامة. هذه القصص ليست لفظية ولكنها تستند أساسًا إلى الصورة والتوضيح. الحوادث والأحداث، على عكس الأنواع الأخرى من الروايات، ليس لها مسار خطي أو غير خطي وتتبع

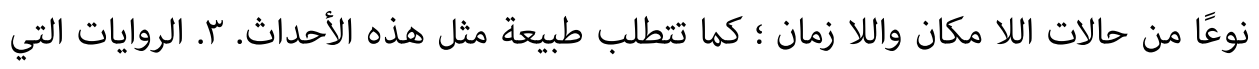
تتكون في نفس وقت الرواية (السرد المتزامن). ومن بينها أحداث حياة الرسول وبصفة عامة أحداث سيرته. ع. يتم سرد الرواية والأحداث بالتناوب وواحدة تلو الأخرى (السرد المزود). ومن الأمثلة على هذه الرواية قصة ولادة مريم ويحيى وعيسى، التي وردت بالتناوب في سورة آل عمران. تشجع هذه الطريقة من رواية القصص أسلوب "القصة في القصة". بالطبع، يبدو أن السرد اللاحق هو النمط السائد في القصص القرآنية. ومن الأمثلة على هذه الرواية قصة ولادة مريم ويحيى وعيسى، التي وردت بالتناوب في سورة آل عمران. تشجع هذه الطريقة من رواية القصص أسلوب "القصة في القصة". بالطبع، يبدو أن السرد اللاحق هو النمط السائد في القصص القرآنية. يلعب الزمان والمكان دورًا كبيرًا في القصة. من العناصر الرئيسية للقصة الزمن، وهو سياق جميع الأحداث في القصة، وتنعكس فيه أفعال الشخصيات في القصة. لطاما تم النظر في الوقت وتنظيره نظرًا لأهميته في القصة. يتضح من مجموعة المحتويات أن قصص القرآن هي اكتشاف لأعمال ومتابعة لأحداث تم نسيانها أو إهمالها لغرض معين. لذلك، فإن قصص القرآن لا تذكر الأحداث فحسب، بل هي عبارة عن مجموعة مختارة من الامم السابقة التي تم من خلالها السعي وراء غرض معين وتتوقع غرض معين. وهكذا، مع الدراسات التي أجريت في بنية القصص القرآنية، بغض النظر عن اختلافاتها الجوهرية والموضوعية مع القصص غير القرآنية، أي 
تفوق الأبعاد التربوية في التمسك بعناصر السرد من المقدمة إلى خلق الاحداق والتوصيف والعنصر الزمان والمكان.، وما إلى ذلك، بنية مرغوبة ومعالجة خاصة، لذلك من خلال الاستفادة من الملمس الفني والبنية القوية والممتعة، يتم تقديم التدريج الصادق فى الرواية بأجمل طريقة. المصادر القرآن الكريم

بحراوي، حسن، (•199 م)، بنية الشكل الروائي؛ الفضاء الزمن- الشخصيه، بيروت: المركز

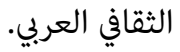

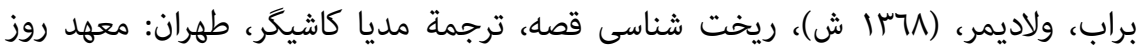

$$
\text { للنشر. }
$$

• جينت، جيرارد، (199V م)، خطاب الحكاية، ترجمة: محمد معتصم والآخرون، الطبعة الثانية،

$$
\text { المجلس الأعلى للثقافة. }
$$

• •

$$
\text { رجبي، محمود وهمكاران، (זوسا ش)، روش شناسى تفسير قرآن، قم: جعفرى. }
$$

سعيد عطية، مطاوع، (T . - م)، الاعجاز القصص فى القرآن، قاهره: معهد الآفاق العربية.

$$
\text { سيد قطب، (10اعاق)، التصوير الفني في القرآن، بيروت: معهد سينا للنشر. }
$$

شجاع يوريان، ولى الله، (זوسا ش)، تأملى در شاخصههاى قصه در قرآن، - الأدب العربي (كلية الآداب والعلوم الإنسانية، جامعة طهران)، المجلد الخامس، العدد الثاني. الطباطبائي، سيد محمدحسين، (IrVV ش)، داستانهاى قرآن وتاريخ انبياء در الميزان، جمع

$$
\text { وإعداد حسين فعال، طهران: سبحان. }
$$

الطباطبائي، سيد محمد حسين، (זوسا ش)، تفسير الميزان، ترجمه سيد محمدباقر موسوى همدانى، قم: منشورات إسلامية تابعة لجمعية معلمي حوزة قم. قنادي، صالح، (1/با ش)، آشنايى با معارف قرآن، تفسير موضوعى (1) قصههاى قرآن، مركز المصطفى(ع) الدولي للترجمة والنشر. محمدي اشتهاردي، محمد، (01با ش)، قصههاى قرآن، طهران: معهد نبوى للنشر. 


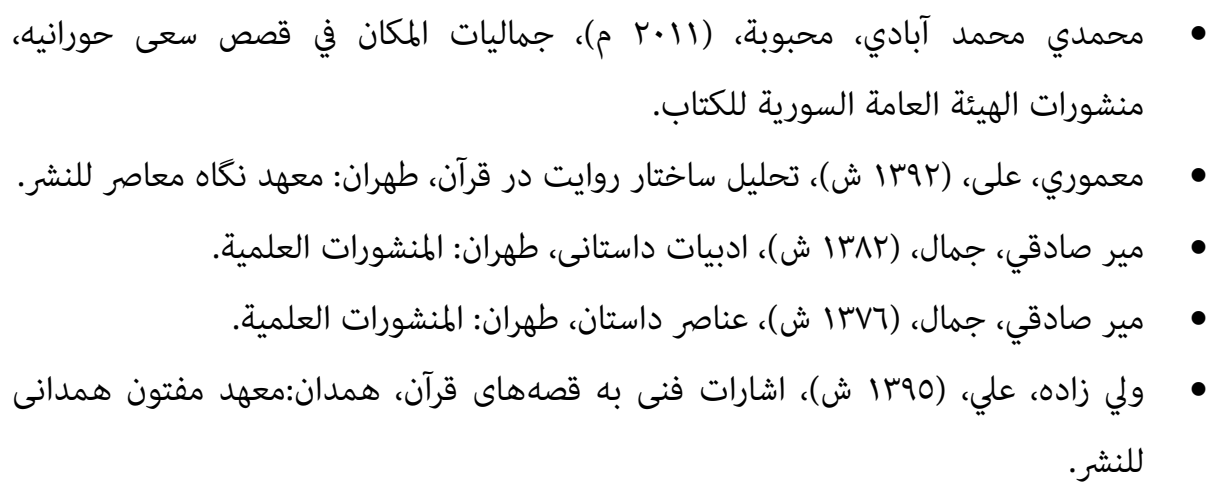

\section{References}

- The Holy Quran

- Bahravi, Hassan, (1990), The Structure of the Narrative, SpacePersonality, Beirut: The Arab Cultural Center.

- Propp, Vladimir, (1989), The Morphology of the Story, translated by Kashigar Media, Tehran: Rooz Institute for Publishing.

- Gérald, Genta, (1997), Al-Khattab Al-Aqayyah, Translator: Muhammad Mutasim and the others, second edition, The Supreme Council of Culture.

- Hosseini, Seyyed Abolghasem, (2000), Artistic Basics of Quran Stories, Tehran: Taha Al-Thaqafi Institute.

- Rajabi, Mahmoud et al., (2013), Methodology of Quran Interpretation, Qom: Jafari.

- Saeed Atiyah Muta'a (2006), The Miracle of Stories in the Qur'an, Cairo: Contributed to the Arab Horizons.

- Sayyid Qutb, (1415), The artistic image in the Qur'an, Beirut: Sinai Publishing.

- Shoja Pourian, Waliullah, (2013), Reflect on the story of his character, the story of the Qur'an, - Arabic literature (College of Arts and Humanities, University of Tehran), Volume Five, Second publication.

- Tabatabai, Seyyed Mohammad Hussein, (1998), Stories of the Qur'an and the history of the prophets in Al-Mizan, Compilation and codification, Hossein Faal, Tehran: Subhan.

- Tabatabai, Seyyed Mohammad Hussein, (2013), Tafsir Al-Mizan, translated by Seyyed Mohammad Baqir Mousavi Hamedani, Qom: Islamic publications belonging to the Society of Qom Seminary Teachers. 
- Qanadi, Saleh, (2006), Familiarity with the teachings of the Qur'an, thematic interpretation (1) of the stories of the Qur'an, Al-Mustafa $(\mathrm{POH})$ State Center for Translation and Publishing.

- Mohammadi Eshtehardi, Mohammad, (2006), Stories of the Quran, Tehran: Al Nabavi Publishing House.

- Mohammadi Mohammadabadi, Mahboubeh, (2011), Jamaliyat al-Makan fi Qasas Sa'i Houranieh, Publications of the Syrian Public Authority for the Book.

- Mamouri, Ali, (2013), Analysis of the structure of narration in the Qur'an, Tehran: Negah Contemporary Publishing Institute.

- Mir Sadeghi, Jamal, (2003), Fiction, Tehran: Scientific Publications.

- Mir Sadeghi, Jamal, (1997), Elements of Story, Tehran: Scientific Publications.

- Valizadeh, Ali, (2016), Technical references to the stories of the Quran, Hamedan: Muftoon Hamadani Institute for Publishing. 


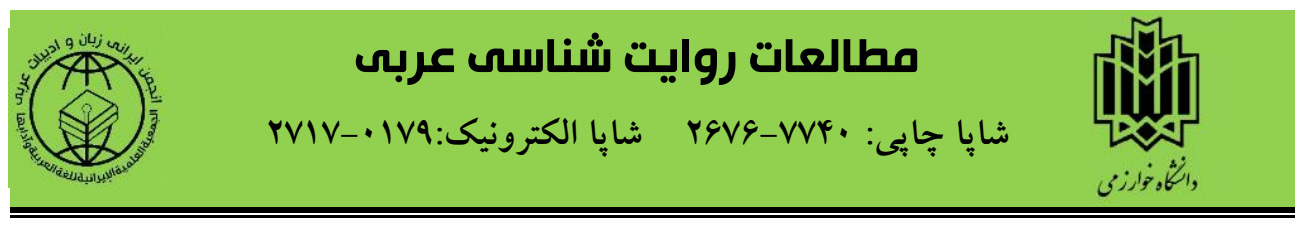

\section{ساختار و شيوه قصص قر آن با رويكرد آراء مفسران شيعى}

kazemian@iaurasht.ac.ir رايانامه:

عضو هيئت علمى كروه الهيات و معارف اسلامى، دانشعاه آزاد اسلامى، رشت، ايران.

در قرآن كريم، بسيارى از مطالب ارزنده و سودمند بهصورت قصه توسط خداوند متعال به تصوير كشيده است و

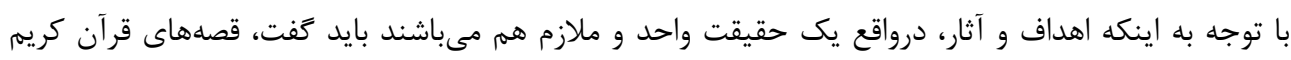

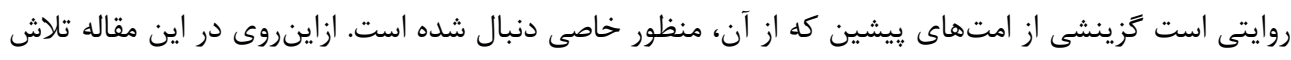

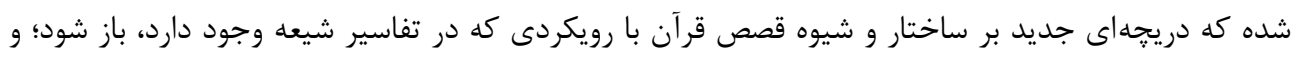

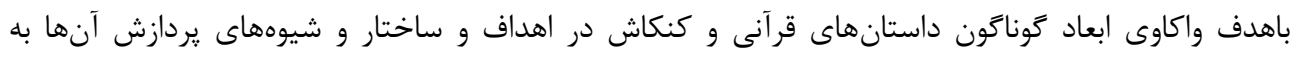
تحقيق يرداخته شود. در اين يزوهش تلاش مىشود عناصر قصهاى قرآنى با روش ويزهاى در تصويريردازى

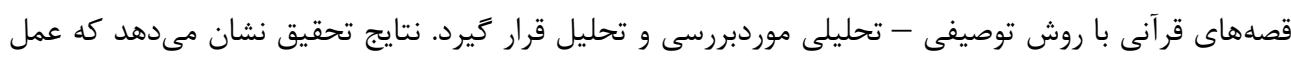

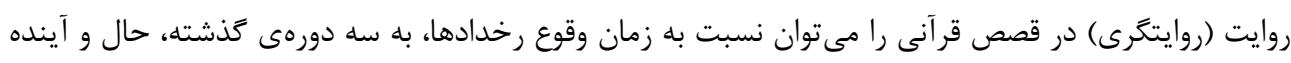

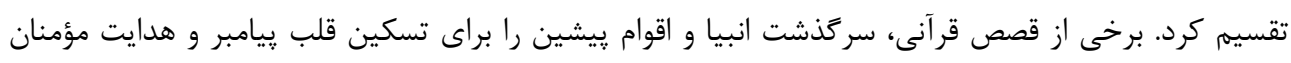

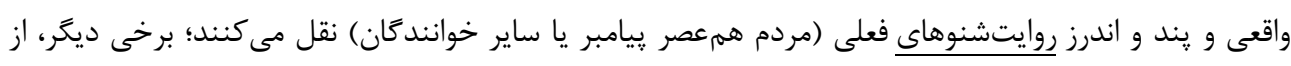

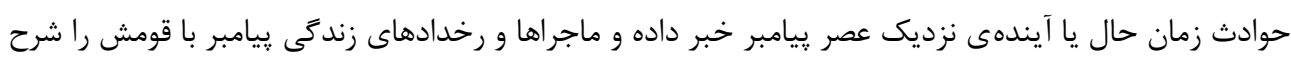

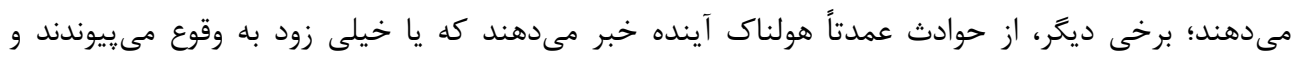

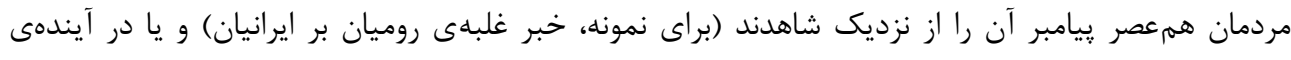

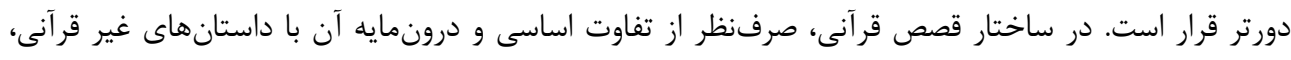

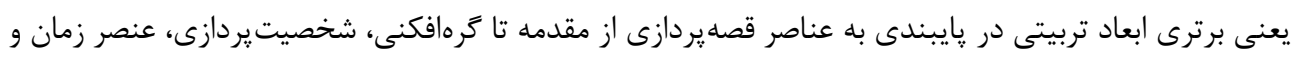

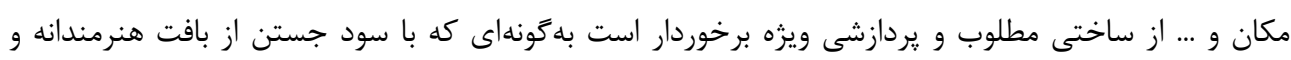
ساختارى محكم و دلنشين صحنهيردازى صادقانه به زيباترين شكل ارائه كرديده است.

كليدوازهها: قصص قرآن، مفسران شيعى، مفهوم شناسى، بررسى ساختار و شيوه نقل قصه. 
استناد: كاظميان، زيبا. بهار وتابستان ( FF (1). ساختار و شيوه قصص قرآن با رويكرد آراء مفسران شيعى، مطالعات

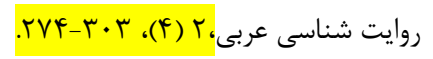

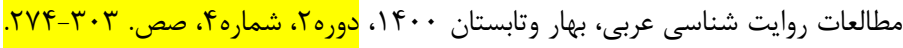

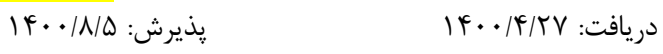

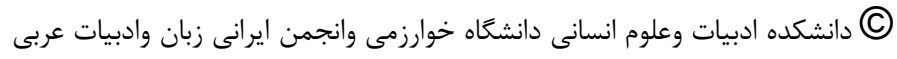

